\title{
MuseipedagogiK OCH LIVSLÅNGT LÄRANDE
}

\section{Ritva Palviainen}

När man talar om museipedagogik, rör sig diskussionen vanligen kring skolor och daghem. Av undervisningsmetoder stiger oftast fram traditionella utställningsvisningar, som baserar sig på modellinlärning och workshops, som bygger på learning by doing -principen. Museer kan dock tjäna många olika undervisningsnivåer och åldersstadier. De är en förträfflig plats också för individuell inlärning. I museernas samlingar och forskning möts det mänskliga livets hela spektrum, det konkreta och det abstrakta, praktik och teori, det privata och det offentliga på ett unikt sätt och man kan blicka tusentals år bakåt i tiden. Museerna svarar vidare för forskningsuppgifter och vård av kulturmiljön. Ämneskrets och inlärningsomgivning vidgar sig utanfor museet till vars och ens vardagserfarenheter. Det livslänga lärandets princip och flerformsundervisning har en idealisk plats i museerna!

I Finland är museiverksamhetens syfte enligt lagen (1166/1996) att upprätthålla och öka medborgarnas kunskap om sin kultur, sin historia och sin miljö. Museerna skall sörja för och främja forskning, undervisning och information på området genom att ta till vara, forska $i$, bevara och ställa ut föremål och annat material om människan och hennes miljö. För museiverkets, statens konstmuseums, riksomfattande specialmuseers, landskapsmuseers, regionala konstmuseers uppgifter finns dessutom skilda stadgar.

Det finns stora regionala skillnader i museiarbetets betoningar - till exempel om museet är beläget på en ort som präglas av studier, industri, jordbruk eller turism. Om museet ligger på en stimulansrik stu- dieort, måste det satsa mycket på forskning, undervisning och information. Handledningen till kunskapskällor samt handledningen av lärdomsprov och forskning hör som naturliga delar till museets undervisning, åtminstone på universitetsoch högskoleorter. Också folkbildningsarbetets fält bjuder museer på många utmaningar. Museerna bör ha färdighet och kompetens också för vuxenutbildning.

ERFARENHETER AV FOLKBILDNINGSARBETE OCH UNDERVISNING AV ÄLDRE MÄNNISKOR

Som huvudsyssla arbetar jag som museilektor i Jyväskylä, en stad med starka studietraditioner, belägen i inre Finland. Min 
Ritva PaLVIAINEN

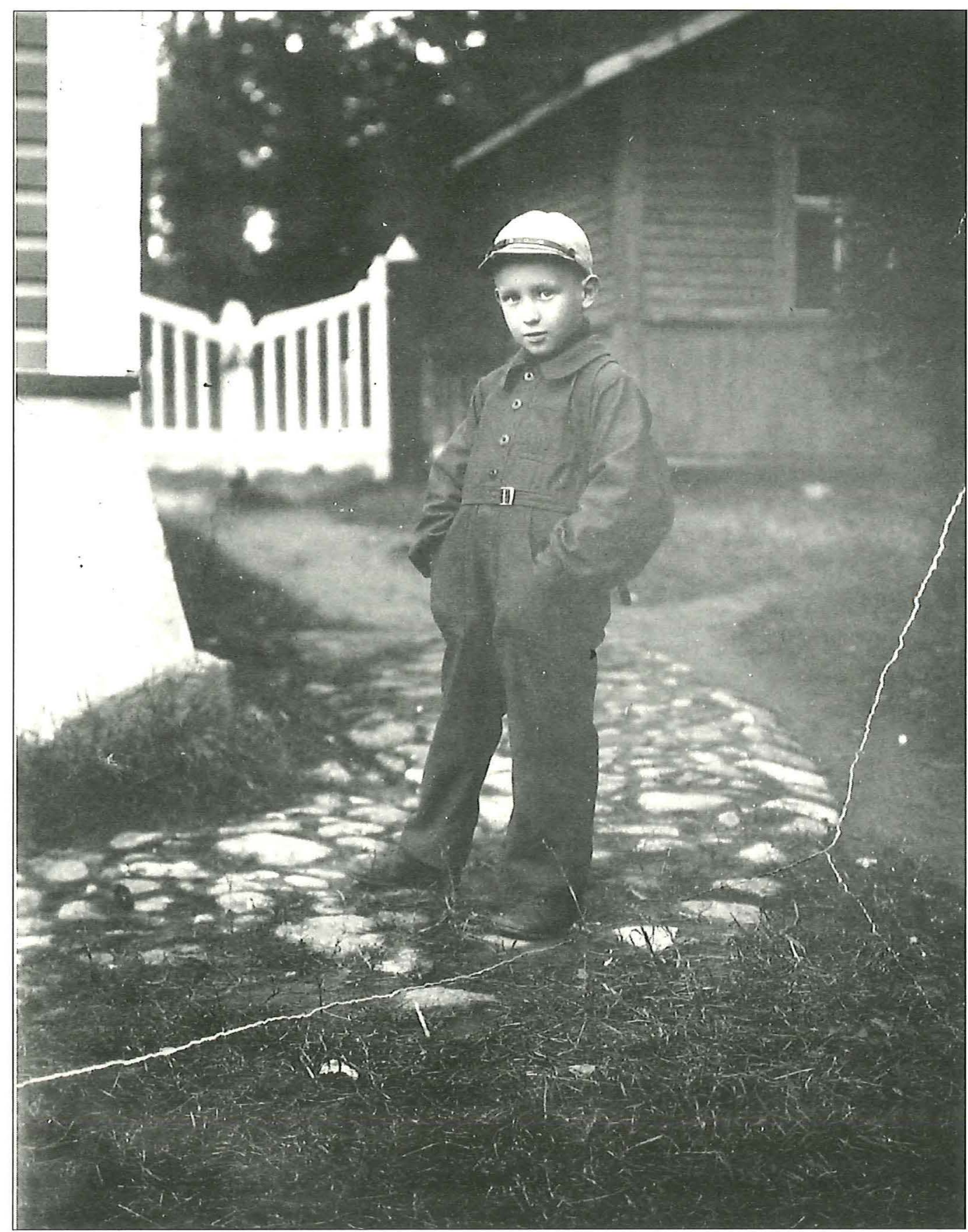


Olli Kosonen i början av sin skolväg $i$ Kerimäki vid börnet av sitt hem Sievälä 1.9.1931. Huset byggdes vid Finlands största träkyrka av Ollis morlfarforäldrar ar 1914. Foto av modern Ester Kosonen 1931. Olli Kosonens fotosamlingar.

Olli Kosonen fick sin studentmössa på midsommaraftonen 1943, som andra pojkar som deltagit $i$ kriget, undantagsvis utan studentskrivningar. Tio pojkar avlade studentexamen vid Nyslott lyceum. För militäruniformens skull kunde mössan inte sättas på huvudet. Foto av Fotoateljé L. Jänis, Nyslott. Olli Kosonens fotosamlingar.

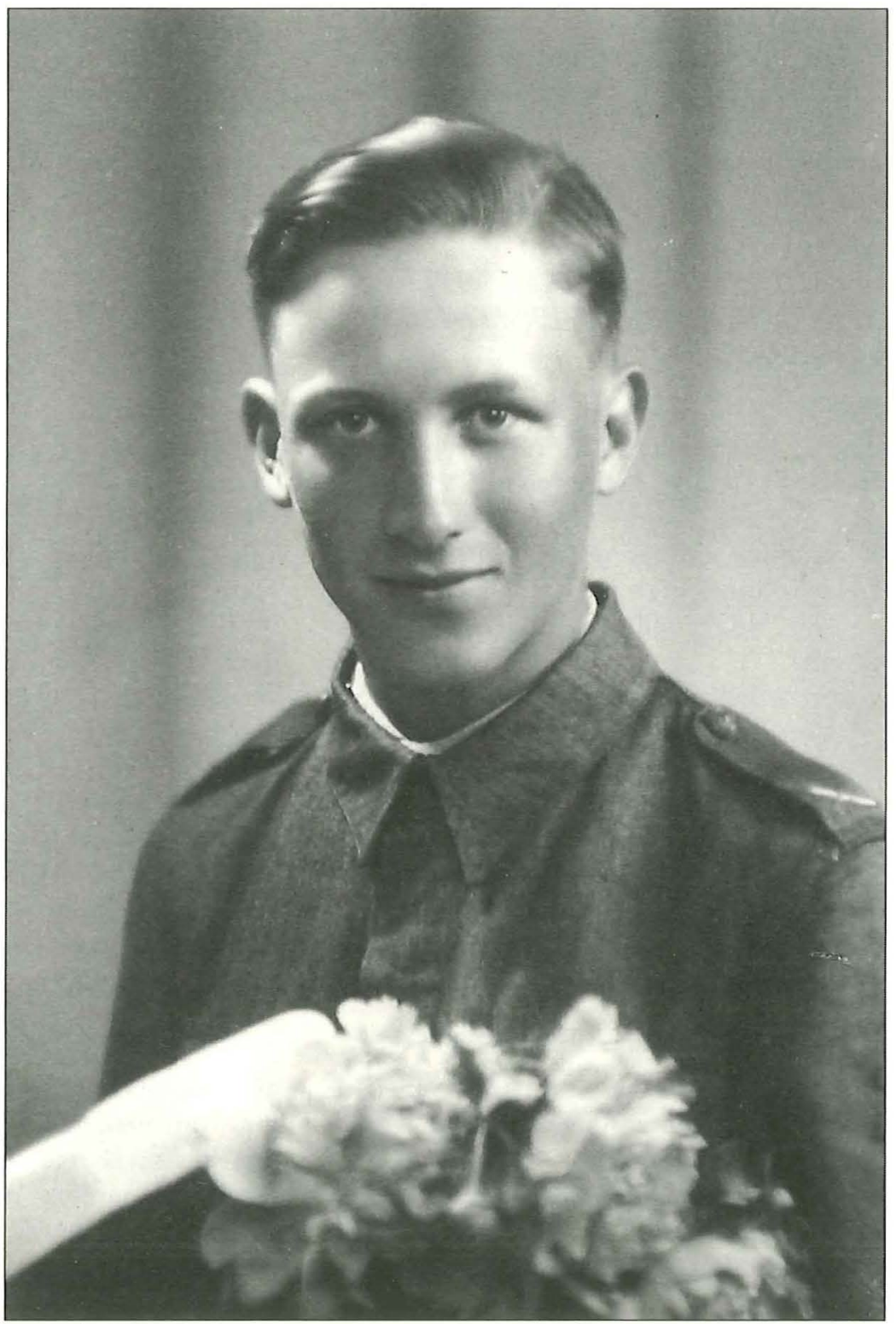

arbetsplats är ett kulturhistoriskt landskapsmuseum, Mellersta Finlands museum. Undervisningen täcker alla nivåer från barn i daghemsåldern till universitetsstu- derande samt historie- och traditionsintresserade. Som bisyssla undervisade jag som timlärare vid Jyväskylä stads arbetarinstitut i en traditions- och historiecirkel, 
18 Jyväskylä för och nu, under åren 1990-99. Sedan 1993 har jag arbetat som seminarieledare i traditionsseminariet vid "den tredje åldersperiodens universitet» i Jyväskylä. Undervisningserfarenhet har jag också från många andra håll.

\section{"DEN TREDJE ALDERNS UNIVER-}

SITET" (SENIORUNIVERSITETET) I JYVÄSKYLÄ

Universitetsverksamhet för åldrade startades i Finland år 1985. Först började Jyväskylä med verksamheten på våren och på hösten kom Helsingfors med. Verksamhet ordnas numera vid sammanlagt nio universitet.

"Den tredje ålderns universitet" syftar till att:

- upprätthålla och förbättra en åldrande människas fysiska, psykiska och sociala status;

- befrämja jämställdhet i bildning och undervisning;

- samarbeta med planerare av gerontologisk forskning och praktiskt ålderdomsarbete;

- konkretisera det livslånga lärandet för hela livsbågen.

Programmet planeras i samarbete med de studerande. Verksamhetsformerna i Jyväskylä är bl.a. följande:

- tvärvetenskaplig föreläsningsverksamhet;

- seminariearbete;

- små frivilliga studerandegrupper;

- forskningsverksamhet;

- exkursioner och studieresor;

- publikationsverksamhet;

- möten på nationell och internationell nivå;

- projektarbeten med olika samarbetspart- ner (som ny målgrupp bl. a. äldre arbetslösa);

- information om det öppna universitetets studier (och vid behov vägledning av studerande som vill avlägga akademiska vitsordsstudier (poängstudier).

Verksamheten är särskilt viktig i Finland just nu, när de stora efterkrigsåldersklasserna närmar sig pensionsåldern. Antalet studerande är för närvarande cirka 1000 och studerandenas ålder varierar mellan 45 och 92 år, medan genomsnittsåldern är 63 år.

"Den tredje ålderns universitet» förverkligas i samarbete med Jyväskylä universitet, Jyväskylä sommaruniversitet och Jyväskylä stad. Verksamheten finansieras huvudsakligen med studieavgifter och upphandlingsavtal med staden. Det finns verksamhet även i andra kommuner och i dem täcks kostnaderna med studieavgifter och kommunernas bidrag. Verksamheten stöds årligen också av undervisningsministeriet, som har definierat verksamheten av den tredje ålderns universitet som en specialform av öppet universitet.

Till förvaltningsorganisationen hör ledningsgruppen och planeringsgruppen vid senioruniversitetet. Till ledningsgruppen hör studerandeföreträdare, representanter för universitetets specialistinstitutioner och Jyväskylä stad. Ledningsgruppen svarar för planerings- och utvecklingsarbetet samt för nationella och internationella kontakter. Planeringsgruppen sätts ihop av studerande. Till den hör även två representanter för generalföreläsningar och en från varje seminariegrupp.

Senioruniversitetet i Jyväskylä är medlem i det år 1989 grundade riksomfattande förhandlingsrådet för verksamheten vid 


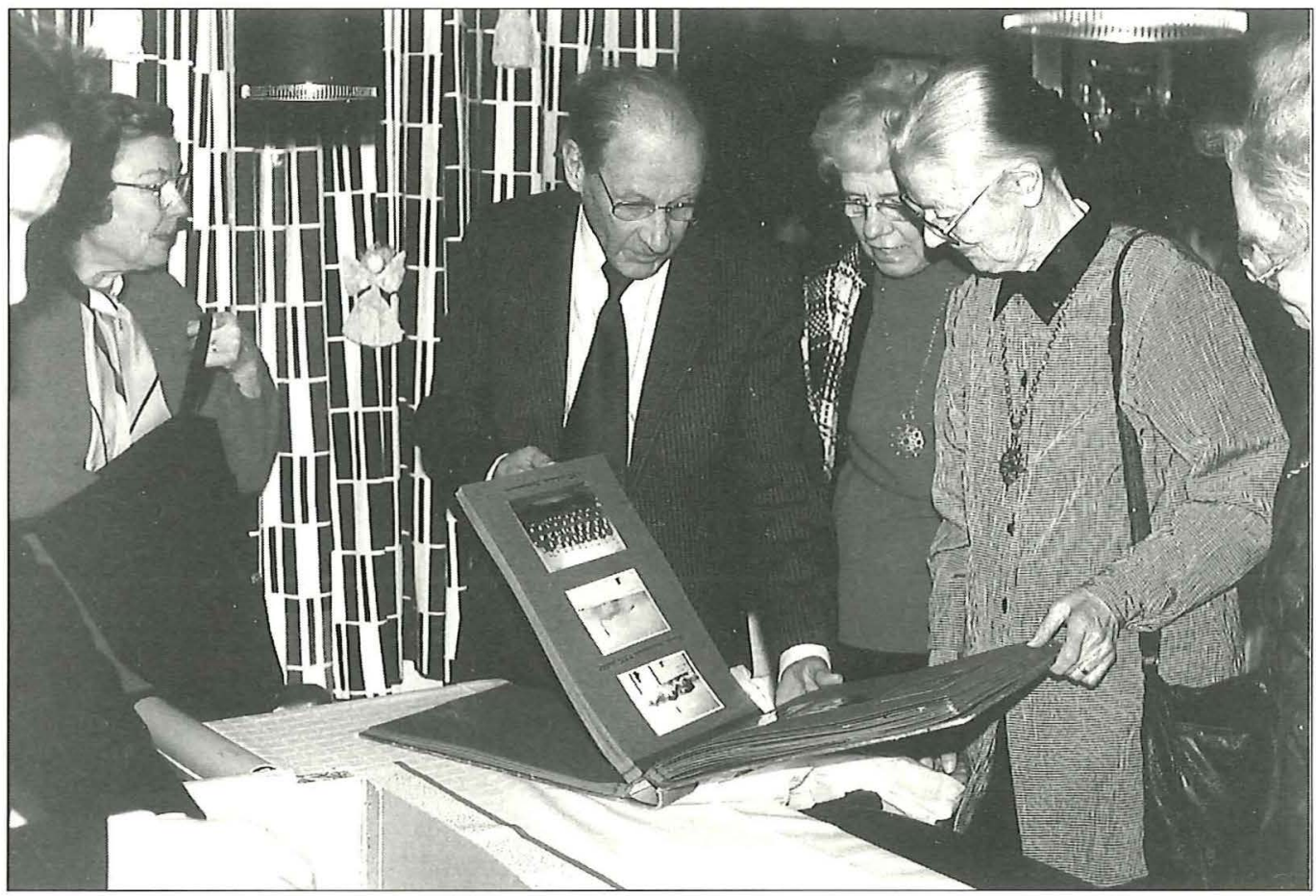

Ordspråket "Lärdom livet igenom» har blivit verklighet $i$ Olli Kosonens liv. Diplomingenjörsexamen vid Tekniska högskolan garanterade en karriär $i$ metallindustrin under hela arbetstiden 1948-86, forst $i$ Helsingfors och därefter i Jyväskylä. Olli Kosonen är en aktiv studerande och verksambetsutvecklare vid Senioruniversitetet $i$ Jyväskylä. Här visar han deltagarna i traditionsseminariet ett fotoalbum frän Statens gevärsfabrik. Frain vänster Tellervo Salminen, Sirkka Ruotsalainen, Eeva Vuorinen och Anni Häkkinen. Foto av Anneli Hietaluoma 1998. Fotografens fotosamlingar.

den tredje ålderns universitet. Rådet är sammansatt av universitetsorternas enheter, som svarar för denna verksamhet. Det deltar internationellt i takorganisationen för universitet för den tredje åldern $A I U$ $T A$ (Association Internationale des Universités du Troisième Age). Internationellt samarbete förverkligas också inom ramen av EU-projekt som Learning in Later Life (Sokrates) och Adult Education \& the Museum i samarbete med Mellersta Fin'ands museum (Sokrates).

\section{TRADITIONSSEMINARIET}

Traditionsseminariet vid Senioruniversitetet har fungerat i sin nuvarande form sedan år 1993. Seminariet samlas under universitetets terminer vartannat år och varannan vecka på Mellersta Finlands museum. Seminarieplatsen är museikaféet och seminariet samlas på kvällstid två timmar åt gången. Seminariet leds av författaren. De studerande är åldrade människor, födda på 1910-30-talen. Den äldsta är född år 
1910. Fastän alla nu bor i Jyväskylä, är många födda, har vuxit upp eller gjort sitt livsverk på annat håll. Utbildningsnivån varierar från några folkskoleår till högskoleexamen. Förenande faktorer är åtminstone intresset för traditionsskrivande samt gemensamma upplevelser från krigstiden. Antalet studerande har varit 8-15 per termin.

Kostnaderna av seminariet har delats så att Senioruniversitetet betalar seminarieledarens lön samt seminariepublikationernas redaktions- och tryckkostnader. Mellersta Finlands museum för sin del bidrar med utrymmen, läromedel, studiematerial och vid behov foton för publikationer utan kostnader.

\section{HUR SEMINARIET ARBETAR}

Seminariets mål är att bevara tradition och självupplevd historia på olika sätt samt att sammansätta en publikation baserad på seminariearbeten. Alla vet redan vid ankomsten, att man själv väntas arbeta $\mathrm{i}$ seminariet: dit kommer man inte endast för att lyssna. Undervisningen omfattar orientering i metoder, arkiv och litteratur. Seminariets teman diskuteras och beslutas gemensamt. Var och en väljer ett tema, som intresserar och tar itu med arbetet. De studerandena får vid behov individuell handledning. Under terminen läses seminariearbeten högt och kommenteras. Att dela erfarenheter på det här viset upplevs som särskilt viktigt. Deltagarna skaffar bilder för sina skrifter antingen ur egna, andra privata eller offentliga arkiv och antecknar information om bildernas innehåll. Redaktören bearbetar skrifter och bildtexter till publiceringsbar form och planerar publikationens utseende.

\section{AMNET SOM INTRESSERAR MEST - ARBETE}

Temat som valdes för det första seminariet var olika faser i människolivet: barndom och ungdom, skoltiden, arbetslivet och pensionstiden. Deltagarnas egna minnen och erfarenheter aktualiserades. Ända från första seminariet har betydelsen av foton betonats, deras informationsvärde, rätta bevarande, samt antecknande av information bunden till fotona. I andra seminariet var viktpunkten på arbete och fritid, fast gränsen mellan dem var svår att dra ännu för några decennier sedan: även fritiden gick under efterkrigsåren åt till sysslor, byggande, trädgårdsarbete, sömnad och dylikt. Skrifterna baserade sig på egna erfarenheter och på intervjuer. I tredje seminariet var huvudtemat bebyggd miljö. $\mathrm{Nu}$ lärde man sig att använda källor, att skriva fotnoter och att avfatta en källförteckning. Eftersom utbildningsnivån varierar så mycket, har dock var och en kunnat välja sina arbetsmetoder själv. Till exempel kan användning och uppgifter om källor vara helt oöverkomligt. Skillnaden är detsamma som att spela på gehör eller efter noter.

I alla seminarier har arbetet varit ett tema som man inte kan förbigå. Krigstiden och åren efter krigen betydde hårt arbete och var en väldig utmaning också för kvinnor. Arbetsåren med alla sina minnen är en sak, som man vill berätta om för efterkommande generationer. Den gemenskap, som arbetsmemoarerna andas, är numera svårt att nå. En av studerandena berättade, att han med sina skrifter vill ge hopp för dagens arbetslösa; man har ju tidigare också klarat av svårare tider. 


\section{PUBLIKATIONER}

Seminariet samlas vartannat år. Under mellanåren har seminarieledaren på sin fritid redigerat och ombrutit illustrerade, häftade publikationer av de studerandes skrifter, varav tre hittills har utkommit:

- Näsa av elfenben och våta blickar. Skörd av traditionsseminariet av universitet för den tredje åldersperioden(1994)

- Fran kattvecka till sommarlov. Arbete och arbetsfylld fritid (1996)

- Baggvåg och Pussö. Arbeten och trakten i våra minnen (1998).

Av den sistnämnda har för synskadade utarbetats en version, som man kan lyssna på som syntetiskt tal eller läsa via punktskriftskärm. Dataversionen får man från Centralförbundet för synskadade.

Namnen på publikationerna kan låta komiska, men de baserar sig på skrifterna. 'En näsa av elfenben' fick en ung skolpojke då han skadades svårt $\mathrm{i}$ ansiktet och förlorade synen under bombningarna av Helsingfors år 1944. 'Våta blickar' kastades mot en vandrande båtmästare av landsbygdens unga krigsänkor, som förlorat sina män. 'Kattvecka' kallades i gångna tider tjänstefolkets frivecka, föregångaren till lagstadgad semester. 'Baggvågar' tillverkades hos ett vågföretag i Helsingfors. 'Pussö' kallades en ö, där manliga och kvinnliga patienter på ett lungsotsanatorium i mellersta Finland gjorde närmare bekantskap med varandra under betraktande ögon av sanatoriesamhällets barn.

\section{VAD JAG LÄRT AV SEMINARIET}

I vuxenutbildning är respekt för den andras livserfarenhet och livsåskådning grundsaker. Att dela erfarenheter genom diskussion lämpar sig bra för flerformundervisning. Genom att dela erfarenheter och kunskaper blir både deltagarnas och lärarens kunskaper mångsidigare. När alla deltar aktivt $\mathrm{i}$ undervisningen och mono$\log$ förvandlas till dialog, föds en känsla av gemensamt ansvar, som upprätthåller gruppanda och motivation.

I samband med vuxenutbildningen har jag också varit tvungen att fundera om jag talar om uppfostran eller om undervisning och jag har kommit fram till det sistnämnda. Jag kan vissa saker och jag kan undervisa i dem, men har jag behov eller förmåga att uppfostra människor, som är äldre än jag? Många gånger känns det, att åldrade studerande uppfostrar och undervisar läraren och det ökar tillfredsställelsen av arbetet.

Vuxenstuderande är krävande och lärarens ribban höjs. Vardagskunskaper och konster bär inte tillräckligt långt. I samband med vuxenundervisningen konstaterade jag, att ämnesstudier i museiämnen och museologi inte ens räcker $\mathrm{i}$ ett museum. Man måste även skaffa sig pedagogisk kompetens för att åtminstone i huvuddrag behärska undervisningens tradition, synpunkter, metoder och terminologi. En väsentlig skillnad mellan museiarbete och undervisning är att objektet i museernas bevarande- och forskningsarbete är museiföremålet, men i undervisningsarbetet människan som lär.

Jag har också kommit fram till att vuxenutbildningens metodik kan tillämpas på mycket yngre, även lågstadieelever. Så har vi redan gjort i samband med vissa projekt. I dem har deltagit människor i olika åldrar från lågstadiet, högstadiet, gymnasiet och universitetets lärarutbildning. Det 
22 finns inga hinder för att då också ta elevernas föräldrar eller morföräldrar med.

Åldrade människor har kunskaper, färdigheter, livserfarenhet och tid. Deras historie- och traditionsintresse kan ur museets synpunkt vara fruktbart på många sätt, speciellt, när de uthålligaste har nått nästan professionell nivå. Alldrade människor kan berika museets kunskapsförråd, bild-, arkiv- och föremålssamlingar. Nya användargrupper och arbetsmetoder ger möjlighet att utveckla museiarbetet innehållsmässigt och att värdera det också ur en annan än besökarantalets synvinkel.

Traditionsseminariet vid Senioruniversitetet i Jyväskylä är med i EU-projektet Adult Education and the Museum (Sokrates) som ett exempel på museernas vuxenutbildningsprogram.

\section{$K \ddot{A L L O R}$}

Hietaluoma, Anneli ja Rossi, Jaana, toim., Jyväskylän Ikääntyvien yliopisto. Toimintakertomus 1998-1999. Jyväskylä 1999.

Jyväskylän Ikääntyvien yliopisto.

http://www.cec.jyu.fi/U3A. Syyslukukausi 1999 [ohjelma].

Lag om ändring av museilagen $\mathrm{Nr}$ 1166/1996.

Palviainen, Ritva, toim., Norsunluinen nenä ja kosteita katsantoja. Jyväskylän ikääntyvien yliopiston antologiasarjan julkaisu 4. Jyväskylä 1994.

Palviainen, Ritva, toim., Kissaviikosta kesälomaan. Työtä ja työntäyteistä vapaa-aikaa. Jyväskylän ikääntyvien yliopiston antologiasarjan julkaisu 6 . Jyväskylä 1996.

Palviainen, Ritva, toim., Pässivaaka ja Pususaari. Työt ja tienoot muistoissamme. Jyväskylän ikääntyvien yliopiston antologiasarjan julkaisu 9. Jyväskylä 1998.

\section{SUMMARY}

The role of museum education

at a university of the Third Age

Museum education is most often connected with the cooperation between museums, preschools and schools. The best known teaching methods are traditional guided museum visits and workshops. Museum education is often considered as a supplement to exhibitions. Museums have much more to give. Museums have the expertise of their personnel, their collections, archives, publications and research, which reach outside the museum walls to the cultural landscape, built environment, sites and monuments - to everyone's everyday experience. All these offer diverse alternatives for many different ways of teaching and for lifelong learning. Museum education is, indeed, for all and museums should have the competence to handle and offer adult education too.

The Museum of Central Finland and The University of the Third Age in Jyväskylä, Finland, have worked in cooperation for a long time. The seminar on Tradition (or Cultural heritage) and Oral History has been held every second year since 1993. The students are senior citizens, interested in cultural heritage, history, discussion and writing. The seminar gives them theoretical and practical tools for recording heritage and for writing about it. The aim of the seminar is to produce a publication based on the articles written by the students. The photographs and other pictures come mainly from their own or other private collections. Three illustrated paperback books edited by the seminar leader have been published to date. The seminar was accepted as a case study for a Socrates Project in Adult Education and the Museum sponsored by the European Commission.

Ritva Palviainen är museilektor vid Mellersta

Finlands museum, Jyväskylä.

Adr: Mellersta Finlands museum, PB 634,

SF-40101 Jyväskylä

Fax +358-14624933 email: ritva.palviainen@jkl.fi 